\title{
Introduction to ZhuhaiJinwan District Urban Landscape Sculpture Design
}

\author{
Zhexin Liu \\ Zhuhai College of Jilin University \\ Zhuhai, China
}

\author{
Bing Han \\ Zhuhai Nanping Middle School \\ Zhuhai, China
}

\begin{abstract}
Landscape sculpture plays an important role in the construction of urban culture and landscape, because it not only increases the bright spot for the city, but also satisfies the public demand of beauty. As part of the city culture environment, landscape sculpture is a rich emotional value and cultural connotation of art, which is also has a certain ecological functions of environmental details. This paper studies the development of history and characteristics of the landscape sculpture, landscape sculpture and city culture, environment. The relationship between analysis sculpture in the urban environment has "series space, value, function and art". The combination of the role of the Jinwan district of Zhuhai city landscape sculpture design should adhere to the "harmony principle, historical cultural principle, people-oriented principle, artistic principle, ecological principle", such as basic principles.
\end{abstract}

Keywords-landscape sculptural sketch; design principle; Jinwan District; Zhuhai

\section{INTRODUCTION}

Sculpture is an important element of the urban landscape, it could use its rich modeling language to convey the unique thoughts and feelings to people. Sculpture interwove with the geographical landscape, garden landscape and architectural landscape of city environment, often it will constitute a characteristic symbol of the city or community. Urban sculptural sketch is an important element of it, it not only can beautify the decoration environment landscape, but also it can convey information which can not be replaced by other art forms or elements. So many urban sculpture pieces are mushrooming all over the city.

During the urban cultural construction of Jinwan District, Zhuhai City, landscape sculptural sketch with artistic quality, time spirit and combined function and aesthetic together will become a beautiful landscape in contemporary Jinawan District, it not only reflect Jinwan's sense of history and sense of culture, but also it indicate the development rate and modernization process of Jianwan District urbanization, which plays an important role in improving the city's image.

\section{THE CHARACTERISTICS OF THE LANDSCAPE SCULPTURAL SKETCH}

The so-called sculptural sketch which compare with large, thematic or monumental urban sculptures, it refers to a small sized sculpture which placed in the public areas of residential areas, recreation area, etc., it does not need large scale and space, no need to be shocked like the large and grand monumental sculpture. It is small sized sculpture with pure artistry or interests. The landscape sculptural sketches no matter Chinese and foreign have been directly influenced by different religions, philosophy and other social ideology in different historical periods. It is the crystal of time, thoughts, feelings and aesthetic concepts, and also the figurative record of social and urban development.

\section{THE APPLICATION OF SCULPTURAL SKETCH IN URBAN ENVIRONMENT}

The proportion of excellent landscape sculptural sketch in urban environment design has been increasingly higher. It carries the development of the city, highlights the city's spirit and cultural background, and is the crowning touch to the city. The Role of Landscape sculptural sketch in urban environment can be divided into the following areas.

\section{A. Connect Space}

Landscape sculptural sketch as an important part of the city beautification construction and urban landscape, it plays an important role in balancing garden space composition and enriching organization visual space, and it can formed a sequence with spatial continuity and transition. Landscape sculptural sketch group guides people from one space to another space, plays a role in spatial orientation and organization of the screen composition, at the same time it divide and connect the space, so to give viewers a unique visual experience. For example: "Zhuhai celebrity sculpture garden" which located in Zhuhai Beishan Park of Culture "Fig.1", the sculpture group shows the distinguished people in modern times from Zhuhai, it exhibits twenty-one historical elites who has a significant position in the history of China. By turning them as bronze statues and placed in the garden space of Beishan. The status is vivid, uses the language of sculpture to reappear the glory of the 21 historical figures, and effectively connects the landscape space of the garden. From the perspective of the cultural environment, it is a history accumulation, and also gives the environment a more profound cultural connotation of the city. 


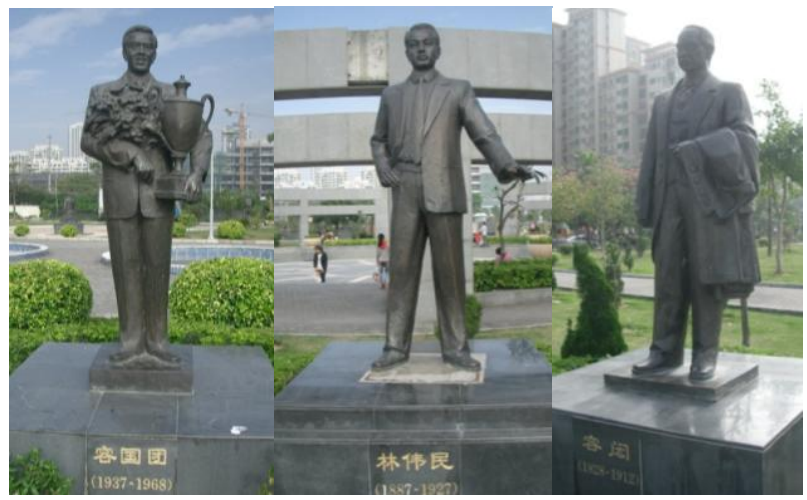

Fig. 1. "Zhuhai celebrity sculpture garden"

\section{B. Reflect the Value}

A sculptural sketch reflect not only the aesthetic concept of designer and users, but also reflects the people's spiritual pursuit, it can reflect the aesthetic and artistic quality of a city's residents, so that it makes the city full of artistic atmosphere and cultural charm. As an important part of the urban landscape, the sculptural sketch not only could shape the urban landscape, improve urban living environment, but also it bears certain urban culture function, it played a role of showing the city culture and lasting the urban context. For example, in Zhuhai scenic Xianglu Wan, stands a giant stone sculpture Zhuhai Yunv, "Fig. 2". She wears beads around her neck, carries a fishnet on her shoulder, trousers at the bottom, highly hold a crystal bright pearl with her hands with joy and shy look to show the bright to the world and sacrifice the treasure to human. The stone sculpture is 8.7 meters high and weight 10 tons, consists of 70 pieces of granite stone, it is the masterpiece of the famous Chinese sculptor Pan He. Today, the sculpture has become a symbol of the city of Zhuhai, and it becomes their pride. The beautiful legend of the girl, along with the popularity of Zhuhai in China, spread more and more widely.

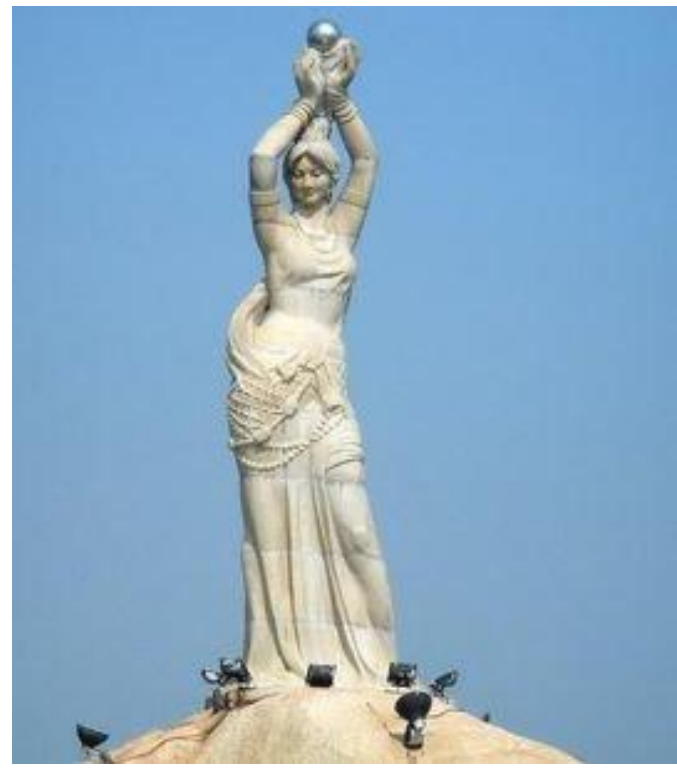

Fig. 2. Giant stone sculpture - Zhuhai Yunv

\section{Combination of Function and Art}

While the landscape sculptural sketch serves the landscape, it also should pay attention to certain functionality which some sculptural sketches could be public service facilities in order to meet a variety of human activities. Some garden sculptures could be table and chair facilities, traffic signs or stops signs in order to provide rest, transportation and other services for visitors. Meanwhile, sculptural sketch must also consider the landscape effect in the environment, sculptures which lack of aesthetic are incomplete. Art and functionality are two fundamental property of the sculptural sketch, both are indispensable and interrelated. For example: Aircraft spread the wings sculpture in Zhuhai Huxin Rd crossing, it uses aircraft spread the wings shape, but the material is polished stainless steel plate, it not only meet the landscaping features and reflects the style of the Jinwan District Air City, but also itself is a functional sculpture to guide transportation. Unfortunately, this sculpture did not retain too long, it forced to tear down when build up the Jinwan District overpass. "Fig.3"

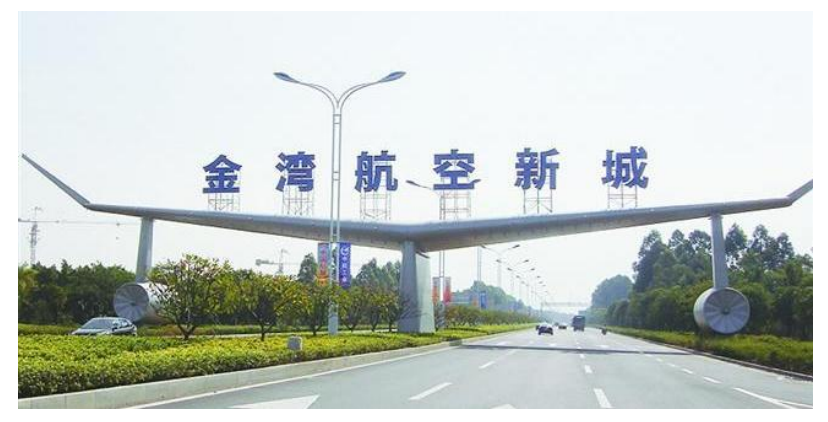

Fig. 3. Aircraft spread the wings sculpture

\section{THE DESIGN PRINCIPLE OF THE JINWAN DISTRICT'S URBAN LANDSCAPE SCULPTURES}

\section{A. Principle of Coordination}

The application of landscape sculptural sketch always in certain environment, so when people see it, they see the overall artistic effect formed with this sketch together with the surrounding environment. In the design and configuration of landscape sculptural sketches, the sketch design should according to local conditions or local situation and then come up with a rational distribution and design ideas, it should consider the overall environment and spatial model to ensure that between the sketch and the surrounding environment and landscape architecture achieve harmony and unity, avoid conflict and confrontation in form, style and color.

\section{B. Principle of History and Culture}

Landscape sculptural sketch is both a sign and symbol of urban culture in microcosm, also is the product of the accumulation of urban culture. Landscape sculptural sketch is the most intuitive and most concentrated expression of a city's spiritual civilization and material civilization, it documented the history of civilization. Once the landscape sculptural sketch has a unique artistic value, it can be a permanent materialized form of national culture with far-reaching meanings. The most 
often mentioned principle in landscape design is to focus on digging local culture, landscape sculptural sketch design also the same.

In addition to inheriting the tradition, landscape sculptural sketch should also have a distinct personality and appearance of the times, and it can not simply copy or reproduce the traditional decorative cultural symbols. On the basis of the characteristics of sculpture language, the Jinwan District landscape sculptures strive to echo with contemporary cultural context, absorbs the essence of the history and culture, to create a contemporary artwork which can reflect the temperament of Zhuhai Jinwan District and also with the historical and cultural heritage. Such as: The third batch of national intangible cultural heritage "Sanzao Hewu" and other landscape sculpture sketches.

\section{Principle of People-oriented}

Landscape sculpture should pursue people-oriented philosophy, and gradually form a humanized design oriented, consider more about the human's psychological needs on the elements of shape, style and volume number. The first health theme park in Zhuhai Jinwan District built a number of public health facilities and landscape sculptures which aimed at promoting the health. The park divided into reasonable diet, regular exercise, smoking cessation\& diet restriction, psychological balance four thematic areas, skillfully blend propaganda, sports and landscape together.

\section{Principle of Artistry}

Landscape sculptural sketch need to play a role in beautifying the environment in a domestic environment, the aesthetic function is the first property, landscape sketch through its shape, quality, color and texture to show its image characteristics to the people, to express certain feeling to meet people's aesthetic interest, but also should show certain cultural connotation at the same time. The Jinwan District landscape sculptural sketch insist on the sustainable development point of view, grasp the pulse of the historical background and the times, follow the trend of the art development, each piece is given to the profound cultural connotations which make it more vitality. Such as: Landscape sculptural sketch design on green road of Jinwan District "Fig. 4" "Fig. 5".

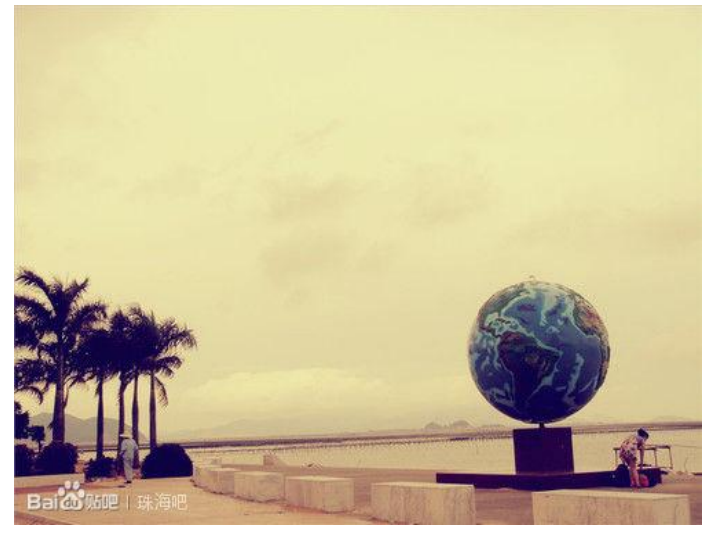

Fig. 4. Landscape sculptural sketch design on green road of Jinwan District.

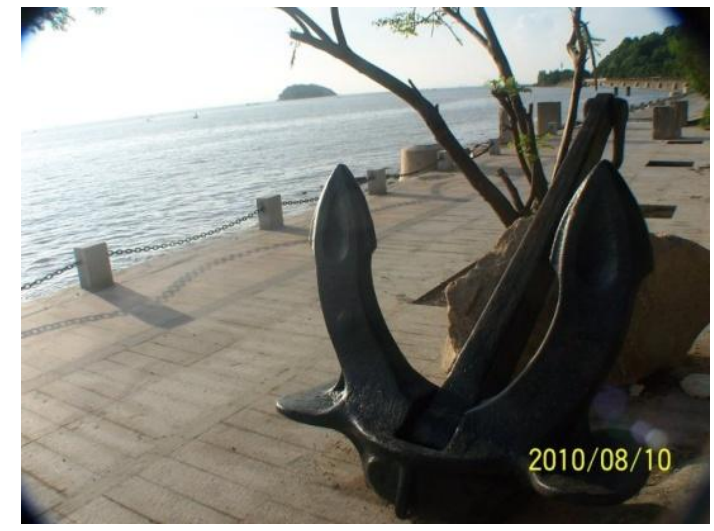

Fig. 5. Landscape sculptural sketch design on green road of Jinwan District.

\section{E. Principle of Ecology}

Under the requirements of constructing a ecological garden city landscape, in terms of design modeling and structure also requires landscape sculptural sketch convergence and integration with the surrounding natural environment as much as possible in order to create a harmony symbiotic relationship with nature, reflect the eco-design concept of the "From nature, back to nature". Jinwan park is a waterfront green Wetland Park under construction which built by Jinwan District, a major function of landscape sculptures in Jinwan park is to provide a comfortable and safe place for people's fitness and rest, it will promote the public interpersonal interaction. Jinwan Park has another function which is ecological function of purified air and water. Jinwan Park needs to maintain the "people-oriented, ecological priority" as a precondition to coordinate social and ecological benefits, emphasize the coordination symbiosis between man and nature.

\section{CONCLUSION}

Landscape sculptural sketch is an important element of the urban landscape, and it is the essential part of the urban public space. The interpenetration between landscape sculptural sketch and geographical landscape, garden landscape and architectural landscape of the urban environment, constitute the characteristic symbol of the city or community. Excellent landscape sculptural sketch can improve the aesthetic level of the people and promote urban landscaping. During the urban landscape design of Jinwan District Zhuhai City should adhere to the "the principle of coordination, the principle of historical culture, the principle of people-oriented, the principle of artistry and the principle of ecology" and other basic principles.

\section{ACKNOWLEDGMENT}

This paper is supported by the project fund of "Jinwan District Social Science "12th Five-Year Plan "2015 annual project:" Design and Research of urban landscape sculptural sketch in Jinwan District "(Project number 201521)". 


\section{REFERENCES}

[1] The communist party of China (ZhuhaiJinwan district committee 、 ZhuhaiJinwan district people's government-Opinions on accelerating the construction of culture, 2010.18.

[2] Che Jian-xiu;Plain Analysis About Urban Sculptures In Public Surroundings; Hundred Schools in Arts, No. 1.2009, vol. 106;p:184.

[3] Zheng Ying-Jin, Li Yu-Xue; Features and design strategies of landscape sculpture;Science \& Technology Information, No. 11.2008; p:312.K. Elissa, "Title of paper if known," unpublished.

[4] Zhang Yuan-yuan;YANG Bo; Discussion on the sculpture design in cultural city of dezhou; Journal of Dezhou University; Vol.30,N0.3,Jun.2014;P:103.

[5] Hegel; Aesthetics (Vol. III) volume One; Beijing Commercial Press,1996.M. Young, The Technical Writer's Handbook. Mill Valley, CA: University Science, 1989.

[6] Zhang Chun-jia ,Under the Influence of Contemporary Art in China City Garden Sculpture Sketch Research, Master Thesis ,Agricultural University of Hebei.

[7] Zeng Li-Xia; Pieces of Landscape Architecture Design;South China Agriculture; Vol.6 No.3,Apr.2012,p:47. 